\title{
Improved pasture management can improve profitability and resilience to climate change in northern Australia
}

\author{
$\underline{\text { L.I. Pahl }}^{\text {a }}$, G.L. Whish ${ }^{\text {a }}$, N.D. MacLeod ${ }^{\text {b }}$, J.C. Scanlan ${ }^{\text {a }}$ and R.A. Cowley ${ }^{c}$ \\ ${ }^{a}$ Dept. of Employment, Economic Development and Innovation, Toowoomba, Queensland \\ ${ }^{b}$ CSIRO Ecosystem Sciences, Brisbane, Queensland \\ ${ }^{c}$ Dept. of Resources, Darwin, Northern Territory \\ Email: lester.pahl@gld.gov.au
}

\begin{abstract}
A Northern Grazing Systems (NGS) project is identifying and promoting key management practices to help improve the profitability and sustainability of the extensive beef industry of northern Australia. The project's initial focus was management practices that perform best under current climate, but now the emphasis has turned to exploring the role these practices may play in helping beef producers adapt to changing climate. This paper reports the preliminary results of using a bio-economic modelling (BEM) framework to compare the performance of a range of pasture management practices under current climate and two projections of future climate.
\end{abstract}

The BEM framework used was linked variants of the GRASP pasture growth model and the ENTERPRISE beef herd economic model. The main metric used to compare management practices was average annual profit. Management practices were compared on a representative beef grazing property located near the township of Mitchell, in southwestern Queensland. It has around 1,400 breeders on 17,000 ha of native and improved pasture, and sells weaner steers, surplus heifers and cull breeding cows at local sale yards.

A flexible stocking rate practice, allowing up to $20 \%$ increases and $40 \%$ decreases in stocking rate over 25 years in response to variability in annual forage availability, was compared with fixed stocking rates. A wet season pasture rest for six months once every four years was compared with continuous grazing, and a prescribed fire scheduled to occur every four years was compared with no burning. These management practices were simulated over the last 25 years (1986 to 2010) of current climate at Mitchell, and two projections of climate change. Projections of climate change, representing the range of possible changes in climate, were: 1) a $\sim 3^{\circ} \mathrm{C}$ increase in minimum and maximum temperatures and a marginal (1\%) decrease in rainfall; and 2) a $\sim 3^{\circ} \mathrm{C}$ increase in temperatures combined with a $27 \%$ reduction in rainfall.

The flexible stocking rate practice performed better than fixed stocking rate under current climate. While fixed stocking was sustainable and profitable, in current climate, flexible stocking was able to improve and maintain pasture condition, enabling carrying capacity, annual stocking rates and livestock productivity to increase. Under projected climate change, the modelled carrying capacity of the representative beef property was lower, especially under Projected Climate 2. Fixed stocking rates that were appropriate under current climate were too high under the two projections of climate change. Pasture condition and livestock productivity declined markedly, leading to low or negative average annual profit. The flexible stocking rate practice was able to match stocking rates to declining feed availability and carrying capacity, and therefore adapt the property to Projected Climate 1. However, it was not responsive enough to match stocking rates with the more severe reductions in carrying capacity that occurred with Projected Climate 2. Annual stocking rates were too high, resulting in poor pasture condition and low livestock productivity.

Under current climate, wet season pasture resting enabled pasture condition to improve, leading to increases in carrying capacity, annual stocking rates, livestock productivity and profit, compared with continuous grazing. Prescribed fire, compared to no burning, prevented increases in woody regrowth that reduced carrying capacity, and was better able to maintain pasture and livestock productivity. Pasture resting and prescribed fire were partially successful in mitigating the impacts associated with the lower carrying capacity of Projected Climate 1, but were ineffective under Projected Climate 2 with its even lower carrying capacities where high stocking rates were the dominant influence on biological and economic relationships.

Keywords: Grazing land management practices, bio-economic modelling, climate change, profitability 
Pahl et al., Property profitability and climate change in the extensive grazing lands of northern Australia

\section{INTRODUCTION}

A major Northern Grazing Systems (NGS) project examining herd and grazing land management in the extensive grazing lands of northern Australia was initiated by Meat and Livestock Australia (MLA) (see MacLeod et al. 2011, this volume). This project is identifying and promoting the adoption of management practices that may improve the profitability and sustainability of the extensive beef grazing industry of northern Australia. Management practices are being evaluated using a combination of beef producer knowledge, principles developed from previous field research (McIvor et al. 2010), and the insights gained from the application of bio-economic modelling (BEM).

This paper reports the preliminary results from using a BEM framework to compare the performance of a range of pasture management practices under current climate and two projections of future climate. A flexible annual stocking rate practice was compared with fixed stocking rates, wet season pasture resting was compared with continuous grazing, and prescribed fire was compared with no burning.

\section{METHODS}

A BEM framework was used to explore the relative profitability of pasture management practices on a representative (synthetic) beef property located in the Maranoa-Balonne region of southwestern Queensland, over a period of 25 years (1986-2010).

\subsection{Bio-economic modelling framework}

The BEM framework used to compare the profitability of management practices was linked variants of the GRASP pasture and animal production model (McKeon et al. 2000, Rickert et al. 2000) and the ENTERPRISE dynamic herd economic model (MacLeod and Ash 2001), which allowed a wider range of grazing land management practices to be simulated (Scanlan and McIvor 2010).

GRASP is a dynamic, deterministic, point-based model that simulates soil moisture, pasture growth and animal production from daily inputs of rainfall, temperature, humidity, pan evaporation and solar radiation. Projected annual stocking rates and animal growth (live-weight gain/head/year) for the representative property derived from GRASP were exported as data input to the ENTERPRISE model. The ENTERPRISE model uses the predicted live-weight gain from GRASP to estimate branding rates and mortality rates, and constructs a herd consistent with these rates and the buying/selling rules (MacLeod and Ash 2001). ENTERPRISE predicts total animal numbers and turnoff rates for each year of a simulation period and provides a range of profitability measures, including gross margins and average annual profit.

\subsection{Deriving the representative beef property}

Beef producers, technical staff and the project team developed a representative property during a workshop within the Maranoa-Balonne region. This property, defined in terms of the number, area, land type and carrying capacity of paddocks, and classes of cattle carried, was the basis for simulations of the profitability of management practices. The defined property is based on a self-replacing herd of 1,400 breeding cows and is located near Mitchell in southwestern Queensland. The property is comprised of 17,000 ha of native and improved pasture in seven paddocks that vary in land type and land condition. The property turns off weaner steers, surplus heifers and cull breeding cows at local sale yards. Other information used in the modelling of this property included herd culling and selling rules, sales, purchases and a range of direct and indirect costs.

\subsection{Pasture management practices}

The regional workshop identified a range of grazing land management practices that would be evaluated using the BEM framework. Of particular interest was management of annual stocking rates, wet season pasture resting and prescribed fire.

Annual stocking rates - the two management practices compared differed in the extent that stocking rates could be adjusted annually in response to variation in forage availability. The first was a fixed stocking rate, consistent with the safe carrying capacity (SCC) for each land type. The SCC was estimated by simulating pasture condition for a range of stocking rates over the 1986-2010 period, where the fixed stocking rate that maintained (neither increased nor decreased) pasture condition was chosen as the SCC. The second was a flexible stocking rate, involving limited annual changes in stocking rate around the same SCC, as determined by forage availability at the end of the growing season. Stocking rates could be increased by up to $10 \%$ or decreased by up to $20 \%$ each year, but during the 25 -year simulation period the maximum extent of change in stocking rate was restricted to an increase of $20 \%$ and a decrease of $40 \%$, relative to the SCC. 
Wet season pasture resting - continuous grazing was compared with a six-month wet season pasture rest that occurred once every four years. With continuous grazing, stocking rates varied annually in accordance with the flexible stocking rate practice described above, and again were set to maintain pasture condition over the 25 -year simulation period. The pasture rest practice involved a regular cycle of resting pastures once every four years, for six months, starting at the beginning of December. Four of the seven paddocks that started the simulation in poor condition were rotationally rested over the 25 -year simulation period. The cattle taken out of paddocks during pasture rest were agisted locally, with agistment costs included in economic comparisons. Annual stocking rates again varied in accordance with the same flexible stocking rate practice, and were allowed to increase in response to improved pasture condition due to resting.

Prescribed fire - no burning was compared with a prescribed fire scheduled to occur in spring once every four years. The four paddocks to be burnt, three with poplar box trees and one with cypress pine, were set to good condition at the start of the simulation (as opposed to poor condition for spelling and stocking rate) and contained trees that grew from an initial tree basal area (TBA) of $2 \mathrm{~m}^{2} /$ ha. The poplar box had an annual growth rate of $10 \%$ and could grow to a maximum TBA of $10 \mathrm{~m}^{2} / \mathrm{ha}$. Cypress pine had a faster annual growth rate of $15 \%$ and could grow to a maximum TBA of $12 \mathrm{~m}^{2} / \mathrm{ha}$. A fire occurred in paddocks at the scheduled time providing the fuel load exceeded $800 \mathrm{~kg} / \mathrm{ha}$ of total standing dry matter. The maximum number of burns possible in each paddock over the simulation period was six, which was achieved in one paddock, while five burns were achieved in two paddocks and four in the remaining paddock. The maximum effectiveness of any one fire was a 75\% reduction in cypress pine TBA and $50 \%$ reduction in poplar box TBA, which occurred when the fuel load exceeded $2800 \mathrm{~kg} /$ ha. Stocking rates for both no burning and burning practices varied annually in accordance with the flexible stocking rate practice described previously.

\subsection{Current climate}

The period of current climate over which these pasture management practices were compared for the representative beef property was 1986 to 2010 (25 years). Daily climate records for Mitchell (station 43020) were obtained from the Bureau of Meteorology (SILO 2011). The SCC for each pasture management practice was calculated for this 25-year period.

\subsection{Projected climate change}

The Queensland Climate Change Centre of Excellence provided 392 climate change projection files for the representative property at Mitchell. Each represented a combination of global circulation models, $\mathrm{CO}_{2}$ emissions scenarios, sensitivities to $\mathrm{CO}_{2}$ and projection dates. From these, 43 were selected which represented a moderate to high temperature increase (approximately $3{ }^{\circ} \mathrm{C}$ ). These files were then ranked in terms of mean rainfall and two files were selected to represent decile 9 rainfall and decile 1 rainfall. These are referred to as Projected Climate 1 and Projected Climate 2, respectively. For the simulation period, mean rainfall for current climate was $542 \mathrm{~mm}, 535 \mathrm{~mm}$ for Projected Climate 1 ( $99 \%$ of current) and $394 \mathrm{~mm}$ for Projected Climate 2 (73\% of current).

To simulate the positive effects of higher atmospheric $\mathrm{CO}_{2}$ on pasture growth under projected climate change, adjustments to GRASP model parameters were made to represent pasture growth rates at a level of 525 ppm $\mathrm{CO}_{2}$, based on the findings of Stokes et al. (2005).

\section{RESULTS AND DISCUSSION}

A range of simulation outputs of the BEM framework are presented and discussed. To begin with, biological relationships simulated by the GRASP model that help inform differences in profits of management practices are presented. This is done only for current climate, but similar trends were evident for other combinations of management practices and climates examined. Average annual profits and number of years when profits were negative are then discussed for all combinations of management practices and climates.

\subsection{Flexible annual stocking rates}

Figure 1 shows the extent that annual stocking rates, expressed as a $450 \mathrm{~kg}$ adult equivalent (AE), changed in response to each of the management practices during the 25-year period of current climate for one paddock (popular box with silver-leaved ironbark and buffel grass). The flexible stocking rate practice lowered annual stocking rates relative to fixed stocking during the first few years of the simulation period, and then gradually increased them until it reached the allowable limit of increase at around 1992. At this point, annual stocking rates could not increase any further, even though improving pasture condition would have allowed this to occur. Fixed stocking rate is not responsive to pasture condition as it is not allowed to change annually. 


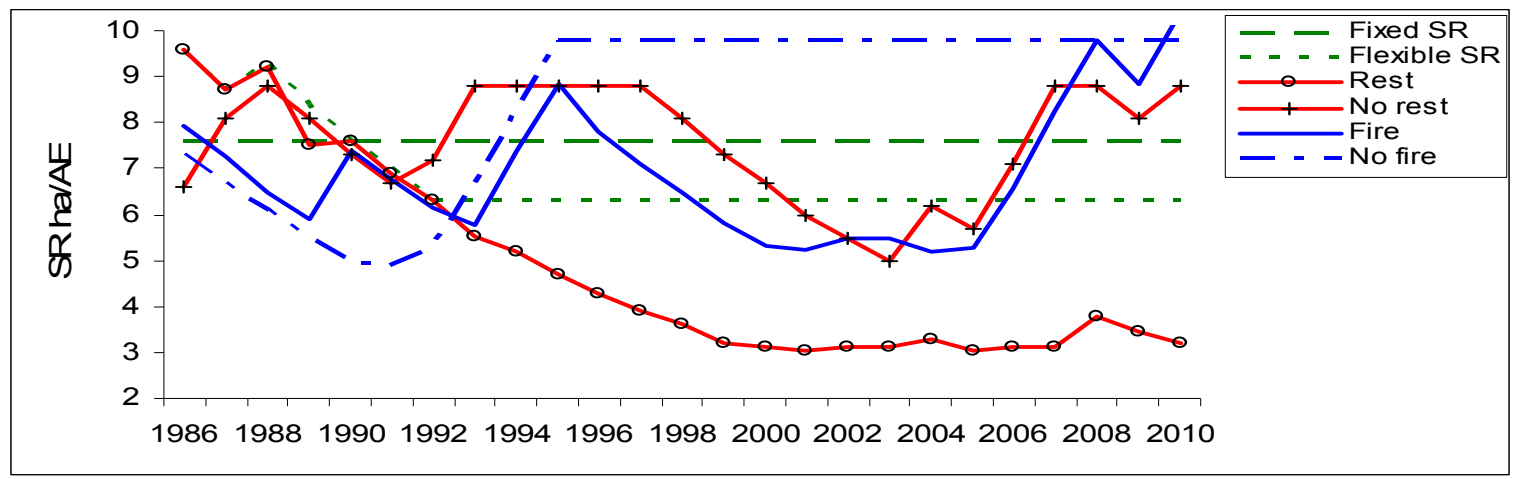

Figure 1. Annual stocking rates (ha/AE) simulated for each of the six management practices in one paddock of the Mitchell representative property, for the period 1986 to 2010.

Figure 2 shows the simulated percent perennial grass content of pasture (an indicator of pasture condition) in the same paddock for each of the management practices examined. Under flexible stocking, percent perennial grass content improved from around $25 \%$ to approximately $90 \%$ during the 25 -year simulation period. This practice lowered stocking rates at the beginning of the simulation period in response to low forage availability, allowing pasture condition to improve. In comparison, percent perennial grass content under the fixed stocking rate practice remained between 10 and $40 \%$ over the same period of time, mainly because there were several occasions when stocking rate exceeded the carrying capacity.

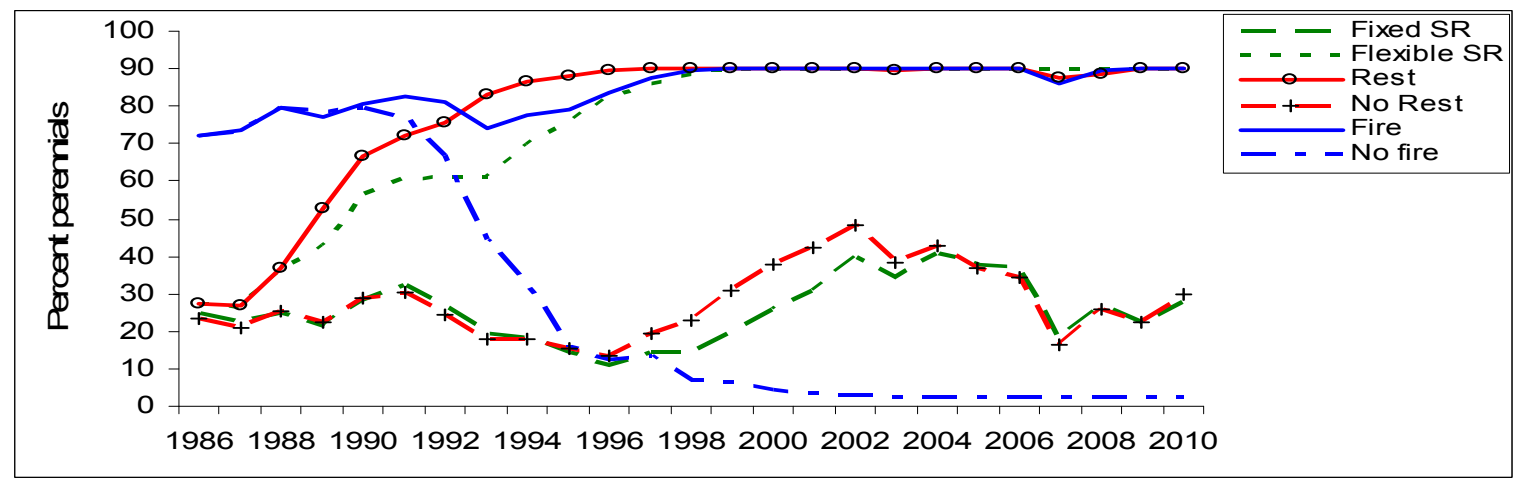

Figure 2. The percent perennial grass content of pastures simulated for each of the six management practices in one paddock of the Mitchell representative property, for the period 1986 to 2010 .

Changes in simulated live-weight gains per head (LWG/hd) in this paddock for each of the management practices examined are shown in Figure 3. Live-weight gains per head for the flexible stocking rate practice are almost always higher than those observed under fixed stocking, and LWG/hd under flexible stocking is never negative. This occurs because the flexible practice is able to improve and maintain pasture condition by matching annual stocking rates to forage availability, minimizing periods of food shortage for cattle.

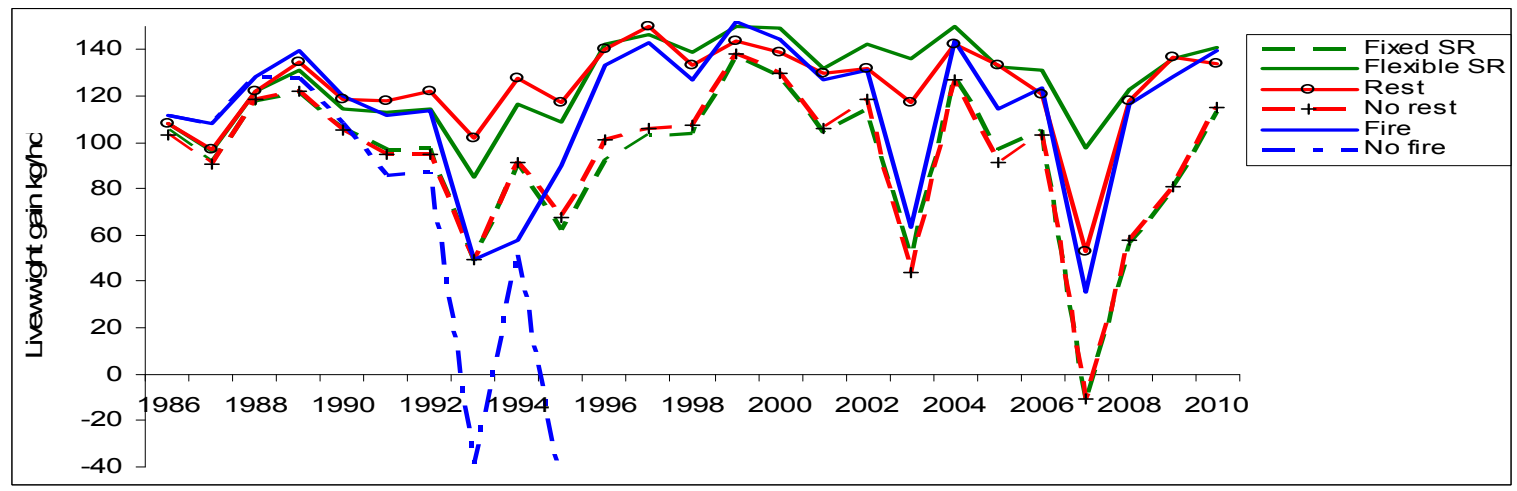

Figure 3. Annual live-weight gain per head $(\mathrm{kg} / \mathrm{hd})$ simulated for each of the six management practices in one paddock of the Mitchell representative property, for the period 1986 to 2010. 
At the whole-property level (all seven paddocks) and under current climate, flexible stocking involving changes in annual stocking rates in response to variation in forage supply yielded a projected average annual net profit of $\$ 100,000$ more than that for fixed stocking (Table 1). The higher profitability of flexible stocking was due to its capacity to improve and maintain pasture condition (Figure 2), resulting in higher stocking rates (Figure 1) and LWG/hd (Figure 3), which together produce higher LWG/ha. This, along with higher branding rates, lower mortality rates and lower supplementation costs that all accrue from improved LWG/hd, are the principal reasons why the flexible annual stocking rate practice was more profitable than a fixed stocking rate practice.

Table 1. Average annual profits and number of years when profit was negative for fixed and flexible stocking rate management practices, for current climate and two projections of climate change.

\begin{tabular}{|l|c|c|c|c|c|c|}
\hline & \multicolumn{2}{|c|}{ Current Climate } & \multicolumn{2}{c|}{$\begin{array}{c}\text { Projected Climate 1 } \\
\left(+3^{\circ} \mathrm{C} \text { and }-1 \% \text { rain }\right)\end{array}$} & \multicolumn{2}{c|}{$\begin{array}{c}\text { Projected Climate 2 } \\
\left(+3^{\circ} \mathrm{C} \text { and }-27 \% \text { rain }\right)\end{array}$} \\
\hline $\begin{array}{l}\text { Management } \\
\text { Practice }\end{array}$ & $\begin{array}{c}\text { Fixed } \\
\text { stocking rate }\end{array}$ & $\begin{array}{c}\text { Flexible } \\
\text { stocking rate }\end{array}$ & $\begin{array}{c}\text { Fixed } \\
\text { stocking rate }\end{array}$ & $\begin{array}{c}\text { Flexible } \\
\text { stocking rate }\end{array}$ & $\begin{array}{c}\text { Fixed } \\
\text { stocking rate }\end{array}$ & $\begin{array}{c}\text { Flexible } \\
\text { stocking rate }\end{array}$ \\
\hline $\begin{array}{l}\text { Average } \\
\text { annual profit }\end{array}$ & $\$ 235,890$ & $\$ 347,630$ & $\$ 51,277$ & $\$ 330,945$ & $-\$ 198,247$ & $-\$ 162,738$ \\
\hline Neg. Yrs. & 4 & 2 & 14 & 1 & 23 & 24 \\
\hline
\end{tabular}

Under Projected Climate 1, flexible stocking was even more profitable than fixed stocking, including far fewer years of negative profit (Table 1). The fixed stocking rate, that was safe under current climate, was apparently too high under Projected Climate 1. Higher evaporation rates and vapor pressure deficits under Projected Climate 1 resulted in considerably lower pasture growth compared with current climate.

Consequently, the fixed stocking rates exceeded the carrying capacity of paddocks, causing declines in pasture condition, and leading to reductions in livestock productivity and average annual profit. Flexible stocking, with its capacity to reduce stocking rates by up to $20 \%$ annually, and by up to $40 \%$ over the 25 -year simulation period, was able to reduce annual stocking rates in response to declining pasture growth rates, and thereby minimise declines in pasture condition, livestock productivity and annual net profit.

There was little difference in the profitability of fixed and flexible stocking under Projected Climate 2, and both were negative and considerably lower than those for current climate. Projected Climate 2 is considerably drier than either the current climate or Projected Climate 1, and the decline in carrying capacity was so great that even the flexible stocking rate practice could not lower stocking rates sufficiently under the simulation rules to prevent declines in pasture condition, livestock productivity and annual net profit. However, these key performance indicators, particularly pasture condition and livestock productivity, may have improved if the stocking rate used at the commencement of simulations was reset in accordance with the reduced carrying capacity under Projected Climate 2 . While a stocking rate flexibility practice that allowed more than a $40 \%$ decrease in stocking rate over the simulation period could have achieved this, it may not have been sustainable without a reduction to the upper limit of stocking rate increase allowed over the same period.

\subsection{Pasture resting}

Pasture resting for six months occurred over the wet season once every four years in four paddocks that contained breeding cows. Compared with continuous grazing, pasture rests resulted in a considerable improvement in pasture condition (Figure 2), which allowed an increase in annual stocking rates (Figure 1), and higher LWG/hd (Figure 3). For these reasons, the average annual profit of resting pastures for six months every four years is approximately $\$ 100,000$ greater than continuous grazing under current climate (Table 2).

Table 2. Average annual profits and number of years when profits were negative for continuous grazing and pasture rest, for current climate and Projected Climate 1.

\begin{tabular}{|l|c|c|c|c|}
\hline & \multicolumn{2}{|c|}{ Current Climate } & \multicolumn{2}{c|}{$\begin{array}{c}\text { Projected Climate } 1 \\
\left(+3^{\circ} \mathrm{C} \text { and }-1 \% \text { rain }\right)\end{array}$} \\
\hline Management Practice & Continuous grazing & Pasture rest & Continuous grazing & Pasture rest \\
\hline Average annual profit & $\$ 206,855$ & $\$ 309,163$ & $\$ 100,513$ & $\$ 157,106$ \\
\hline Neg. Yrs. & 4 & 2 & 6 & 2 \\
\hline
\end{tabular}

Under Projected Climate 1, pasture rest was over $\$ 50,000$ higher than that for continuous grazing, and had fewer years of negative profit. However, the benefits gained from resting pastures were somewhat negated by 
high stocking rates relative to the lower carry capacity evident under Projected Climate 1, resulting in reduced profits. Under Projected Climate 1, the lower carrying capacity of paddocks meant that they were now overstocked in some years, and with this high grazing pressure, their condition deteriorated. Pasture resting enabled land condition to partially improve, and was still generally profitable.

Due to the much lower carrying capacity under Projected Climate 2, the stocking rates could not be sustained, leading to very poor pasture condition and pasture growth, and consequently, negative simulated live-weight gain in many years. Profits are not presented, as they only reflect the dominating influence of high stocking rate. This reinforces the point that if stocking rate is not appropriate for the conditions studied, then other pasture management practices cannot overcome the adverse effects caused by this. Pasture resting is also likely to have been more effective under climate change if the initial stocking rates were aligned with the reduced carrying capacity, but the impact of this on property profitability is yet to be simulated.

\subsection{Prescribed fire}

In the absence of prescribed fire, woody regrowth increased to its maximum TBA by 2001 under current climate (Figure 4). By 1992, the amount of woody regrowth present started to progressively reduce pasture condition (Figure 2) and pasture growth. This reduced the carrying capacity of this paddock which is reflected in the progressively declining annual stocking rates post 1992 (Figure 1). It is also evident in Figure 1 that the flexible stocking rate practice used in conjunction with no burning was attempting to lower annual stocking rates even further, but was prevented from doing so by the limit in total decrease allowed during the simulation period. As annual stocking rates were higher than the carrying capacity of this paddock from 1995 onwards, LWG/hd declined rapidly (Figure 3; LWG/hd after 1995 were consistently highly negative but are not shown). In contrast to this, a prescribed fire once every four years under current climate was able to hold the woody regrowth in this paddock at around $2 \mathrm{~m}^{2} /$ ha over the duration of the 25 -year simulation period (Figure 4). In conjunction with the flexible stocking rate practice this maintained good pasture condition (Figure 2), generally higher annual stocking rates (Figure 1), and relatively good LWG/hd (Figure 3).

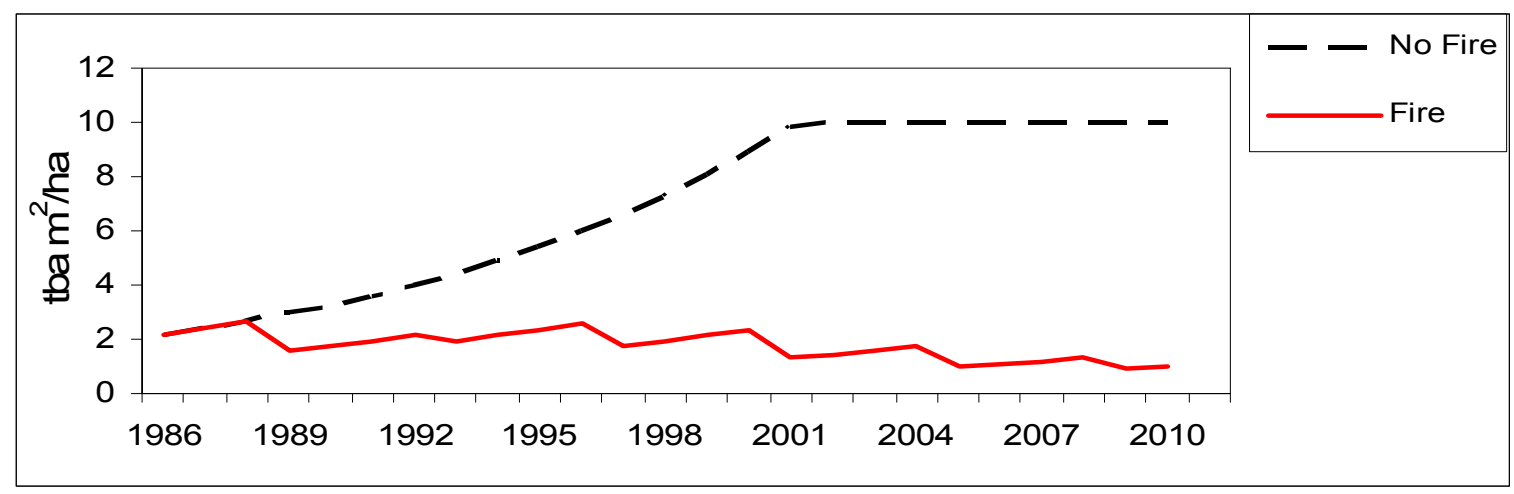

Figure 4. Tree basal area simulated with and without a prescribed fire every four years for one paddock of the Mitchell representative property, for the period 1986 to 2010.

For these reasons, a prescribed fire, scheduled to occur every four years in four paddocks, was on average $\$ 150,000$ more profitable each year than the no burning under current climate (Table 3).

Table 3. Average annual profit and number of years when profit was negative with and without prescribed fire, for current climate and Projected Climate 1.

\begin{tabular}{|l|r|r|r|r|}
\hline & \multicolumn{2}{|c|}{ Current Climate } & \multicolumn{2}{c|}{$\begin{array}{c}\text { Projected Climate 1 } \\
\left(+3^{\circ} \mathrm{C} \text { and }-1 \% \text { rain }\right)\end{array}$} \\
\hline Management Practice & No fire & \multicolumn{1}{|c|}{ Fire } & No fire & \multicolumn{1}{c|}{ Fire } \\
\hline Average annual profit & $\$ 32,253$ & $\$ 181,989$ & $\$ 59,365$ & $\$ 103,679$ \\
\hline Neg. Yrs. & 16 & 4 & 10 & 6 \\
\hline
\end{tabular}

The average annual profit of the prescribed fire practice under Projected Climate 1 was approximately $\$ 43,000$ higher than that for the no fire practice, for the same biological reasons noted above for current climate. The smaller difference in average annual net profit between the prescribed fire and no fire practices compared with that for current climate reflects the decline in carrying capacity associated with Projected Climate 1. Under Projected Climate 2, annual stocking rates regularly exceeded pasture carrying capacity and were the dominant cause of the highly negative profits which are not presented here. 
Pahl et al., Property profitability and climate change in the extensive grazing lands of northern Australia

\section{CONCLUSIONS}

The bio-economic modelling framework used here builds on and extends the findings of field research conducted in the grazing lands of northern Australia. Due to the high costs associated with the long periods of time required for field research, simulation modelling of this type enables more management practices to be evaluated at more locations, under more climate regimes. This gives it the capacity to identify profitable and sustainable management practices that are applicable to a wide range of extensive beef properties operating under diverse conditions across northern Australia.

The modelled carrying capacity of the representative beef property was lower with climate change, especially under Projected Climate 2, which is consistent with and explained in more detail in Scanlan et al. (2011). Fixed stocking rates that were appropriate under current climate were too high under the two projections of climate change, and were neither sustainable nor profitable. A flexible stocking rate practice, involving limited increases and decreases in annual stocking rates, was able to match stocking rates to declining feed availability and carrying capacity, and therefore adapt the property to Projected Climate 1 . However, this form of flexible annual stocking rate management was not responsive enough to match stocking rates with the more severe reductions in carrying capacity that occurred with Projected Climate 2, and could not adapt the property to the changed conditions. A lower initial stocking rate and/or more flexible stocking rate management practices would be required to adapt the property to this degree of climate change.

Pasture resting and prescribed fire partially mitigated the impacts of Projected Climate 1, but not the impacts of high stocking rates relative to even lower carrying capacities associated with Projected Climate 2.

\section{ACKNOWLEDGMENTS}

We are grateful for the funding provided by Meat and Livestock Australia and the Department of Agriculture, Fisheries and Forestry's Australia's Farming Future: Climate Change Research program. We also thank Jane Hamilton, Col Paton and Tim Emery for the property and management practice information they provided for the bio-economic modelling of the Maranoa-Balonne region. Chris Stokes provided valuable assistance in the preparation of the climate change projections.

\section{REFERENCES}

MacLeod, N.D. and Ash, A.A. (2001). Development of a spreadsheet herd dynamics model to assess the economic value of forecasts in extensive grazing enterprises. Oceans to Farms Project Report No.6, CSIRO Sustainable Ecosystems, Brisbane and Townsville. $11 \mathrm{pp}$.

MacLeod, N.D., Scanlan, J.C., Whish, G.L., Pahl, L.I. and Cowley, R.A. (2011). Application of bioeconomic simulation models for addressing land management issues for northern Australia. MODSIM 2011 (this volume)

McIvor, J.G., Bray, S.G., Grice, A.C. and Hunt, L. P. (2010). Grazing management guidelines for northern Australia: Scientific rationale and justification. In: Final report MLA project NBP.0579 - Enhancing adoption of improved grazing and fire management practices in northern Australia: Synthesis of research and identification of best-bet management guidelines. (Ed. J.G. McIvor). Brisbane.

McKeon, G.M., Ash, A.J., Hall, W.B. and Stafford-Smith, M. (2000) Simulation of grazing strategies for beef production in north-east Queensland. In Applications of seasonal climate forecasting in agricultural and natural systems-The Australian experience. (Eds. G. Hammer, N. Nichols and C Mitchell.) pp. 22752. Kluwer Academic Press, Netherlands.

Rickert, K.G., Stuth, J.W. and McKeon, G.M. (2000). Modelling pasture and animal production. In: Field and Laboratory Methods for grassland and Animal Production Research (eds. L. 't Mannetje and R.M. Jones). (CAB International Publishing: New York).

Scanlan, J.C. and McIvor, J.G. (2010). Enhancing Adoption of Best Practice Grazing Management in Northern Australia: Phase one - Integration and Scenario Testing. Final Technical report: Caring for Our Country Project OG084273, Meat and Livestock Australia.

Scanlan, J.C., Cowley, R.A., Pahl, L.I., Whish, G.L. and MacLeod, N.D. (2011). The potential range of impacts of climate change on safe carrying capacities for extensive grazing lands of northern Australia. MODSIM 2011 (this volume)

SILO (2011). SILO meteorology for the land; enhanced meteorological data. Department of Environment and Resource Management, Queensland. http:/www.longpaddock.qld.gov.au/silo/

Stokes, C., Ash, A., Tibbett, M. and Holtum, J. (2005). OzFACE: the Australian savanna free air $\mathrm{CO}_{2}$ enrichment facility and its relevance to carbon-cycling issues in a tropical savanna. Australian Journal of Botany 53: 677-687. 